\title{
Treatment of adult idiopathic ileocolic intussusception with non-operative reduction under fluoroscopic guidance
}

\author{
Ezekiel Wong Toh Yoon ${ }^{1 *}$, Koichi Higashi ${ }^{2}$ and Jun Horiguchi ${ }^{3}$ \\ ${ }^{1}$ Department of Internal Medicine (Gastroenterology), Hiroshima Kyoritsu Hospital, Hiroshima City, Japan \\ ${ }^{2}$ Department of Paediatrics, Hiroshima Kyoritsu Hospital, Hiroshima City, Japan \\ ${ }^{3}$ Department of Radiology, Hiroshima Kyoritsu Hospital, Hiroshima City, Japan
}

\section{Key clinical message}

Intestinal intussusception is rare in adults, often associated with a malignant lesion and usually requires surgery. Preoperative diagnosis is best made using an abdominal CT scan. Unlike in pediatric cases, nonoperative reduction using contrast enema or air is not often employed. However for benign or idiopathic cases, reduction can be attempted before electing for surgery.

\section{Introduction}

Intussusceptions in adults are a rare entity, representing only $1 \%$ of all bowel obstructions and $5 \%$ of all intussusceptions $[1,2]$. In children, intussusception is usually idiopathic and benign, with up to $30 \%$ of patients coinciding with gastroenteritis [3]. Non-operative reduction using air or contrast enemas is sufficient to treat intussusception in $80 \%$ of pediatric patients. In adults however, most intussusception cases are secondary to a pathologic lesion that serves as a lead point that is trapped by peristalsis and then dragged into the distal segment of the intestine, causing the intussusception. Pathologic lesions that serve as potential lead points include malignant tumors, Meckel's diverticulum, strictures or benign neoplasms. Nevertheless, up to $40 \%$ of adult patients may present as idiopathic intussusceptions [2, 4].

We herein report our experience in managing an 18-year-old woman with idiopathic ileocolic intussusception.

\section{Case report}

An 18-year-old woman with no prior history developed intermittent, crampy, abdominal pain that was accompanied with nausea and diarrhea. At initial presentation, she was diagnosed with acute viral gastroenteritis and prescribed probiotics. However, her stool turned bloody and she was admitted into our hospital the following day. Her vital signs were normal and abdominal examination revealed a mass with tenderness in the right lower quadrant.

Laboratory findings on admission revealed only mild leukocytosis $(9,520 / \mu \mathrm{L})$ and no other abnormalities. Abdominal ultrasound showed a mass forming a "donut sign" in the right lower quadrant (Figure 1, arrow). Computed tomography scan also confirmed a "target mass" consisting of two superimposed concentric radiolucent circles in the ileocolic region (Figure 2, arrow). A diagnosis of ileocolic intussusception was made and non-operative reduction using contrast enema was performed under fluoroscopic guidance (Figure 3).

During reduction, examination with contrast enema revealed a filling defect, also known as a "cup-shaped filling" or "claw-like appearance", within the lumen of the proximal portion of the ascending colon which confirms the diagnosis of ileocolic intussusception (Figure $3 \mathrm{~A}$, arrow). Reduction using hydrostatic pressure was successful as indicated by the free flow of contrast agent into the distal ileum (Figures $3 \mathrm{~B}$ and $3 \mathrm{C}$ ). After reduction, her symptoms improved remarkably and

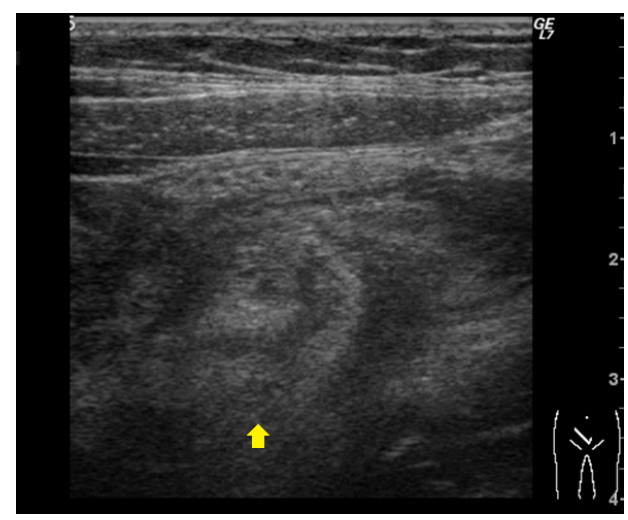

Figure 1. Abdominal ultrasound with arrow pointing to a mass which formed a "donut sign" in the right lower quadrant.

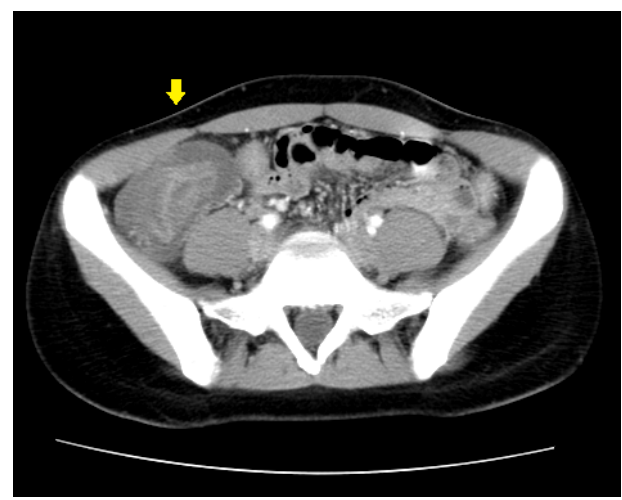

Figure 2. Computed tomography scan confirming a "target mass" consisting of two superimposed concentric radiolucent circles in the ileocolic region.

Correspondence to: Dr. Ezekiel Wong Toh Yoon, Department of Internal Medicine, Hiroshima Kyoritsu Hospital, 2-20-20 Nakasu Asaminami-ku Hiroshima City, Japan; Tel: 8182-879-1111; E-mail: easybs@hotmail.com

Key words: adult intussusception, idiopathic, ileocolic, non-operative reduction

Received: August 12, 2016; Accepted: August 24, 2016; Published: August 31, 2016 


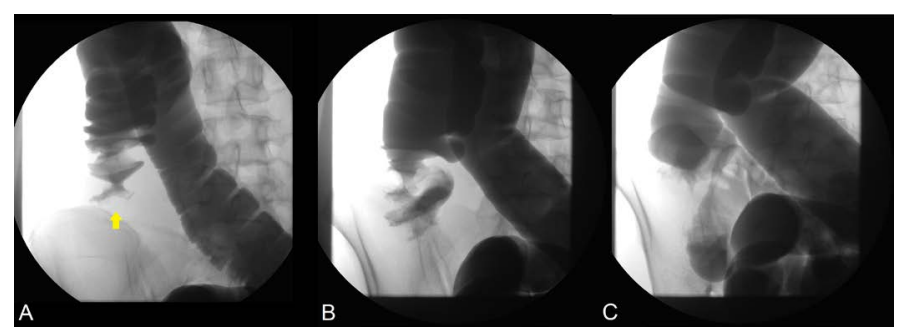

Figure 3. Fluoroscopic imaging of non-operative reduction using hydrostatic pressure from contrast enema.

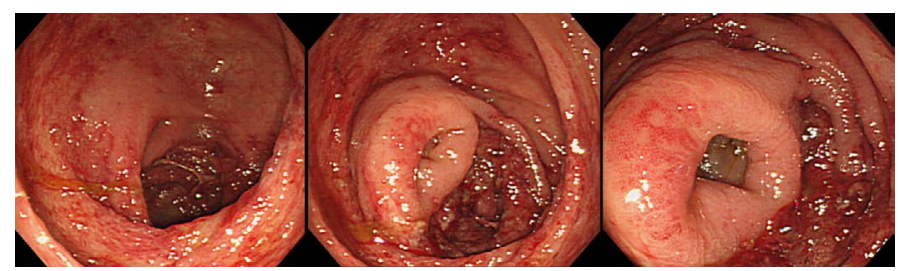

Figure 4. Endoscopic imaging of the cecum and ileocecal valve on the day following reduction.

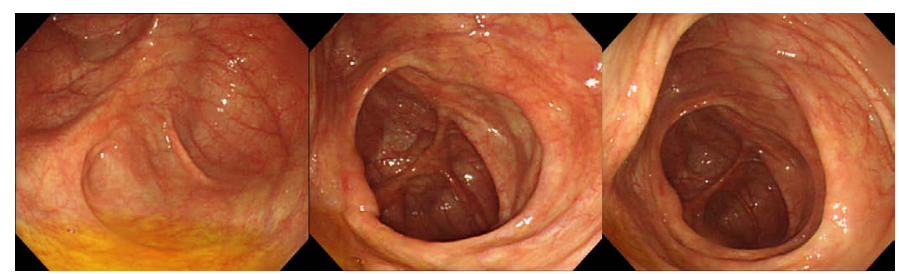

Figure 5. Endoscopic imaging of the cecum and ileocecal valve one month after discharge.

on day 2 after admission, total colonoscopy was performed to check for any lesions that may serve as possible lead points. Although moderate to severe mucosal edema as well as erythema with mild erosions were observed in the cecum and ileocecal valve, there were no lesions (including in the terminal ileum) that could specifically be identified as lead points for intussusception (Figure 4). Biopsy demonstrated inflammatory change that was compatible with ischemic colitis. We regarded these endoscopic findings as ischemic changes secondary to intussusception rather than the cause of it.

On day 4 after admission, oral intake was resumed and she was discharged on day 7 without any complications. One month after discharge, total colonoscopy was again performed, revealing only a healed cecum with no other extraordinary findings (Figure 5). More than 5 years have passed and the patient had no recurrence of intussusception.

\section{Discussion}

Intestinal intussusception is rare in adults, and is typically due to a pathologic lead point within the bowel, which is often malignant $[1,2]$. This lead point is pulled forward by peristalsis so that it prolapses the affected segment of intestine (called intussusceptum) into another segment of intestine (called intussuscipiens). Intussusception is usually classified either according to the etiology (benign lesion, malignant lesion, or idiopathic) or by their location (entero-enteric, ileo-colic, or colo-colic) [2].

Abdominal pain (72-100\%) is the most common presentation, followed by nausea/vomiting (36-52\%) due to bowel obstruction. Other symptoms include diarrhea, constipation, melena, weight loss, fever, and constipation $[4,5]$. Nevertheless, presenting symptoms are nonspecific and up to $20 \%$ of patients may actually be asymptomatic when diagnosed [4]. The classic triad of cramping abdominal pain, bloody diarrhea and a palpable tender mass is rare in adults but was present in our patient.

Abdominal computed tomography (CT) scan is currently considered the most sensitive radiologic method to confirm intussusception. Even then, preoperative diagnosis rates still varies from $50 \%$ to $90 \%$ according to the literature $[5,6]$. Due to the high probability of malignancy as the cause of intestinal intussusception in adults, surgical resection is often viewed as the treatment of choice [6, 7]. Preoperative reduction is not often performed because of theoretical risks such as intraluminal seeding/venous tumor dissemination, perforation and perceived increased risk of anastomotic complications in case surgery is required [2]. However, such as in our case, nonoperative reduction can be attempted when the lead point is thought to be benign or unclear (idiopathic).

Nevertheless, it should be pointed out that it is difficult to distinguish between malignant or benign lesions. Although CT scan or ultrasound may not detect any lesions suspected to be malignant in nature, without direct confirmation by either endoscopy or surgery, malignancy cannot be totally ruled out. It is also equally challenging to predict the severity of ischemic bowel changes that may have occurred due to the intussusception before the reduction is attempted. Therefore non-surgical reduction should be performed only by an experienced clinician, preferably with pre-procedural consultation with a surgical team for back up in the case of perforation or other complications.

\section{Conclusion}

In conclusion, we reported a case of adult idiopathic ileocolic intussusception which was successfully treated with non-operative reduction under fluoroscopic guidance.

\section{References}

1. Azar T, Berger DL (1997) Adult intussusception. Ann Surg 226: 134-138. [Crossref]

2. Marinis A, Yiallourou A, Samanides L, Dafnios N, Anastasopoulos G, et al. (2009) Intussusception of the bowel in adults: a review. World J Gastroenterol 15: 407-411. [Crossref]

3. Buettcher M, Baer G, Bonhoeffer J, Schaad UB, Heininger U (2007) Three-year surveillance of intussusception in children in Switzerland. Pediatrics 120: 473-480. [Crossref]

4. Lindor RA, Bellolio MF, Sadosty AT, Earnest F 4th, Cabrera D (2012) Adult intussusception: presentation, management, and outcomes of 148 patients. $J$ Emerg Med 43: 1-6. [Crossref]

5. Chang CC, Chen YY, Chen YF, Lin CN, Yen HH, et al. (2007) Adult intussusception in Asians: clinical presentations, diagnosis, and treatment. $J$ Gastroenterol Hepatol 22: 1767-1771. [Crossref]

6. Hanan B, Diniz TR, da Luz MM, da Conceição SA, da Silva RG, et al. (2010) Intussusception in adults: a retrospective study. Colorectal Dis 12: 574-578. [Crossref]

7. Takeuchi K, Tsuzuki Y, Ando T, Sekihara M, Hara T, et al. (2003) The diagnosis and treatment of adult intussusception. J Clin Gastroenterol 36: 18-21. [Crossref]

Copyright: (C2016 Toh Yoon EW. This is an open-access article distributed under the terms of the Creative Commons Attribution License, which permits unrestricted use, distribution, and reproduction in any medium, provided the original author and source are credited. 